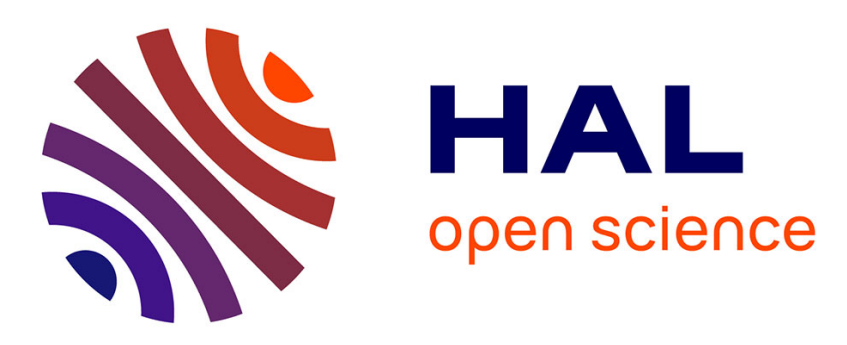

\title{
Mechanical behaviour of different type of shear band connections being used in reconstruction housing in Nepal
}

Santosh Yadav, Yannick Sieffert, Eugénie Crété, Florent Vieux-Champagne, Philippe Garnier

\section{To cite this version:}

Santosh Yadav, Yannick Sieffert, Eugénie Crété, Florent Vieux-Champagne, Philippe Garnier. Mechanical behaviour of different type of shear band connections being used in reconstruction housing in Nepal. Construction and Building Materials, 2018, 174, pp.701-712. 10.1016/j.conbuildmat.2018.04.121 . hal-01780074

\section{HAL Id: hal-01780074 \\ https://hal.science/hal-01780074}

Submitted on 22 May 2018

HAL is a multi-disciplinary open access archive for the deposit and dissemination of scientific research documents, whether they are published or not. The documents may come from teaching and research institutions in France or abroad, or from public or private research centers.
L'archive ouverte pluridisciplinaire HAL, est destinée au dépôt et à la diffusion de documents scientifiques de niveau recherche, publiés ou non, émanant des établissements d'enseignement et de recherche français ou étrangers, des laboratoires publics ou privés. 
Mechanical behaviour of different type of shear band connections

being used in reconstruction housing in Nepal

Santosh Yadav ${ }^{\mathrm{a} *}$, Yannick Sieffert ${ }^{\mathrm{a}}$, Eugénie Crété ${ }^{\mathrm{b}}$, Florent Vieux-

Champagne ${ }^{\mathrm{c}}$ and Philipe Garnier ${ }^{\mathrm{b}}$

${ }^{a}$ Université Grenoble Alpes, Grenoble INP, CNRS, 3SR, F-38000 Grenoble, France

${ }^{b}$ Laboratoire CRAterre, Unité de recherche AECC, École Nationale Supérieure d'Architecture de Grenoble, Grenoble, France

${ }^{c}$ LMDC, Institut National Des Sciences Appliquées de Toulouse, Toulouse, France

*Email: yadv.santos@gmail.com ; http://orcid.org/0000-0002-4239-8518 


\title{
Mechanical behaviour of different type of shear band connections being used in reconstruction housing in Nepal
}

\begin{abstract}
Masonry structures are common in most of the under developed and developing countries in South-East Asia and Nepal is one of those nations which suffered from tremendous loss during earthquake in 2015. These types of structures are strengthened using various traditional and modern techniques, but the sustainability of the approach is obtained when local building culture is taken into consideration. The use of shear bands in masonry structures has been implemented in different nations for several centuries. It is also recommended by Government of Nepal (GoN) through design catalogues for the reconstruction of earthquake resistant buildings. These techniques proved to enhance the seismic performance of the structure but the influence of using different materials and of their configuration in term of dissipation of energy are not quantified. This research work focuses on an experimental approach to determine the mechanical behaviour of different materials (concrete, timber, or bamboo) when used as shear bands. Significant differences were highlighted in the seismic performance behaviour and energy dissipation of shear bands according to the materials, the contact surface areas and the junctions between elements. These results are analyzed in light of the substantial differences in material and labour costs at local levels in each earthquake-affected district. This article covers the experimental research conducted on shear bands and its links with on-site reconstruction activities.
\end{abstract}

Keywords: shear band; masonry building; seismic load; local building cultures 


\section{Introduction:}

Every year, various natural disasters activities take away lives and properties among which earthquake is one of the most significant phenomena occurring due to continuous tectonic movement and accumulation of huge energy in the earth. Nepal is a developing country with almost one-quarter of the population below poverty line and the residential buildings do not meet the minimum standards in most cases (Yogeshwar et al., 2000). On 25 ${ }^{\text {th }}$ April 2015, an earthquake occurred at Barpak (Gorkha district), scaling $7.8 \mathrm{Mw}$ on Richter scale with hypocentre depth of approximately $8.2 \mathrm{~km}$. The main shock was followed by two major aftershocks $6.7 \mathrm{Mw}$ on $26^{\text {th }}$ April and $7.3 \mathrm{Mw}$ on $12^{\text {th }}$ May 2015 causing tremendous losses of human life and properties in highly urbanized areas. The total number of partial and completely collapsed buildings were 302,774 and 775,782 respectively (National Emergency Operation Center, 2015). 98\% of the damaged and collapsed buildings were private houses. The topography of Nepal varies moving from south towards north and so are local building cultures, regarding the house types and the practices associated to them in particular. The houses present in the hilly region of Nepal are mainly made up of partially dressed stones (Mendes, 2015) (Langenbach, 2015) with mud or cement mortar and sometimes even dry stone masonry. These type of unreinforced masonry structures are quite common in most of the under developed and developing countries in South-East Asia. Such structures can be strengthened using several choices of materials and technique. The strengthening and retrofitting of masonry structures using modern composite materials has become quite common in developed countries (Choudhury et al., 2015) (Milani et al., 2017) and turns out to be efficient regarding the structure stiffness and weight (Milani et al., 2010), as well as regarding its reversibility (Triantafillou \& Fardis, 1997). However, in order to increase people's resilience to disasters on the long run, it is necessary to promote rebuilding techniques that cope with inhabitants' empowerment, with the possibility of a self-upgradeability of houses, and with a large-scale reproducibility of the design suggested. Bearing in mind these three pillars, both traditional techniques and modern materials should be integrated, according to their adaptation to local contexts (Porto et al., 2018) (Garnier et al., 2013).

Seismic activities occur all over the world, but the extent of damage varies. The reason behind this variation is the respect of seismic safety rules during the construction works and the building lifespan, on the one hand, and people's understanding of the building behaviour and their respect of the safety measures during seismic activity, on the other hand. When local seismic activity is important, inhabitants and local professionals usually developed "local seismic cultures" over time (Ferrigni et al., 2005). Hence, in order to develop seismic strategies that cope with local conditions, studying historical buildings and traditional construction practices, the material used, and the cultural values related to it is of high importance. These specific building cultures are being lost with the import of international standards, which are not always relevant in the context of the country and often not sustainable. Decontextualized guidelines usually do not cope with local financial and professional capacities and resulting low quality works (Ferrigni et al., 2005). Hence, international standards, if needed, have to be customized to the context of intervention for an effective implementation and even more, so that they are not counterproductive.

Need for scientific results

Following 2015 Nepali earthquakes, there is a high need for starting reconstruction works, which would be safe for upcoming similar events making proper decisions based on social, cultural, political, and environmental factors. To achieve this goal, the GoN published a design catalogue detailing earthquake resistance guidelines (DUDBC, 2015). It includes different types of buildings, most of them with shear bands from various materials, for example timber, bamboo, or concrete. However, people started modifying these technical recommendations during reconstruction works without having proper knowledge on the shear 
bands sensitivity to these modifications. For example, during field surveys by CRAterre and 3SR in 2016 and 2017, several technical issues were observed such as the use of unseasoned timber, reinforcement bars being not properly positioned in concrete shear bands. These changes were mostly for economic reasons, but also because of a lack of properly trained masons. Hence, to find out the physical behaviour of those shear bands more experimental research work is necessary.

The mechanical impact of the shear bands has not been evaluated in the past. This is challenging as shear bands work in masonry wall and could have different impacts in depend of the masonry materials but also on the shear bands materials. The main hypothesis of the objective of a shear bands is to increase the masonry capacity to dissipated energy before collapse. This is provided by the localization of the energy dissipation at its interface between masonry which is softer that the interface between brick/stone masonries. Then, shear bands slide on the masonry and the masonry stay as a monolithic element. This paper presents the first investigation of the impact of a shear wall. It focuses to analyze the capacity to dissipate energy in regards of the material use for shear bands with the development of an experimental device to shear the interface in a quasi-static cyclic loading.

\section{Shear band:}

Timber shear bands have been used for several centuries, and behaved very well during major earthquakes as observed in Europe (Balkanic countries, Greece), Asia (Turkey, Pakistan, India, Nepal, Bhutan), and Latin America (Chile, Bolivia) (Hofmann, 2015). Moreover, during experimental tests, timber reinforced masonry wallets had better resistance to deformation than unreinforced masonry when subjected to compression followed by diagonal compression loading (Vintzileou, 2008). The integration of horizontal wooden elements not only improves their structural behavior but also helps to reduce the risk of collapse due to differential settlements of the ground or the delamination of a masonry wall (Langenbach, 2009). By varying the properties of the horizontal insertions (their shape and thickness) as well as their vertical spacing, it was possible to double the compressive strength of blocks $(10 \mathrm{~cm} * 10 \mathrm{~cm} * 30$ $\mathrm{cm}$ ) and increase their deformation limit as observed from an experiment performed by Lehmann et al at ENAC- EPFL under the supervision of Hofmann (Hofmann, 2015).

Horizontal reinforcement in walls can be used as horizontal bands or ring beams, cross-sections of bands, dowels at corners and junctions along with vertical reinforcement in the wall. As an alternative to the steel reinforcing bar, wooden planks of rectangular sections may be used where timber is available and more economical (Arya et al., 2013). The seismic band should always be continuous and remain in the same level without any dip or change in height (Bothara \& Brzev, 2011).

Among the different types of horizontal wood insertion adopted by vernacular buildings for providing extra resistance to seismic force, the ladder shaped, made up of longitudinal brackets connected by cross ties members, is the most common. The presence of transverse timber ties prevents the delamination of a vertical layer of the wall (Vintzileou, 2008). Transverse timber locking system plays an important role in the case of double layer masonry wall structure as they are very sensitive to delamination and having shear band at different level helps to reduce effective height thickness ratio and hence get low slenderness ratio. With lower slenderness ratio, the arc effect is limited to a shorter length which prevents excessive deformation out of plane (Parajuli, 2009).

The shear band is a member that is used for providing seismic resistance to the low strength masonry structures at different horizontal level using various material as shown in Figure 1 (left). The horizontal continuous beam or band at each level acts as a belt, and the building vibrates monolithically preventing chances of out-of-plane failure by restricting the bending 
deflection, and corner separation as the structure is held together by horizontal band. The shear band at roof level also help in proper connection of roof with the wall and provide support during the seismic action.
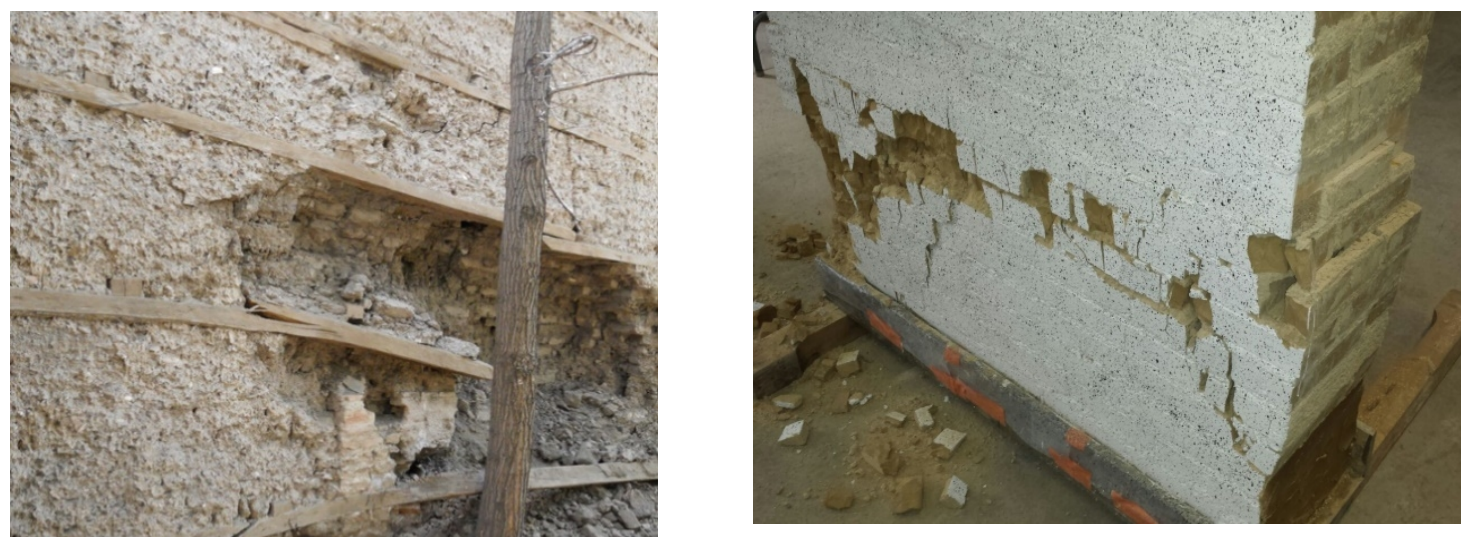

Figure 1. Use of Horizontal timber shear band in Turkey (left) [Photograph copyright: A. Caimi] and prevention of in-plane shear crack propagation with the use of shear band (right) [Photograph copyright: Florent Vieux-Champagne]

Similarly, the use of horizontal shear band helps to prevent the in-plane shear crack propagation as shown in Figure 1 (right). In this way, the crack is limited within the two-shear bands layer that prevents the complete failure of the wall. The sliding behaviour of those shear bands leading to dissipation of energy due to frictional behaviour at the interface layer can been observed. These bands also help to check the horizontal alignment of wall level at a different level during construction.

\section{Shear band in Nepal}

Nepal had experience many strong earthquakes in the past among which the highest recorded earthquake was $8.4 \mathrm{Mw}$ in the year $1934 \mathrm{AD}$ when around 126,000 houses had repairable extent of damage and approximately 81,000 collapsed (NSET-Nepal, 2012). After such an event, people rebuilt their houses implementing timber bands at beam level and bracings in a more systematic way. Many temples that date back to this period were not - or only slightly - damaged during 2015 earthquakes, which reinforce Ferrigni's concept of local seismic cultures. People used their locally available resources and their own skill to build seismic resistant houses and monuments. The National Building Code regarding masonry and RC structures was published in 1994. It recommends the use of horizontal bands/ring beams at plinth, lintel, roof and gable level as a structural reinforcement. But this practice was far too often not implemented due to lack of knowledge among local communities and authorities (Yogeshwar et al., 2000).
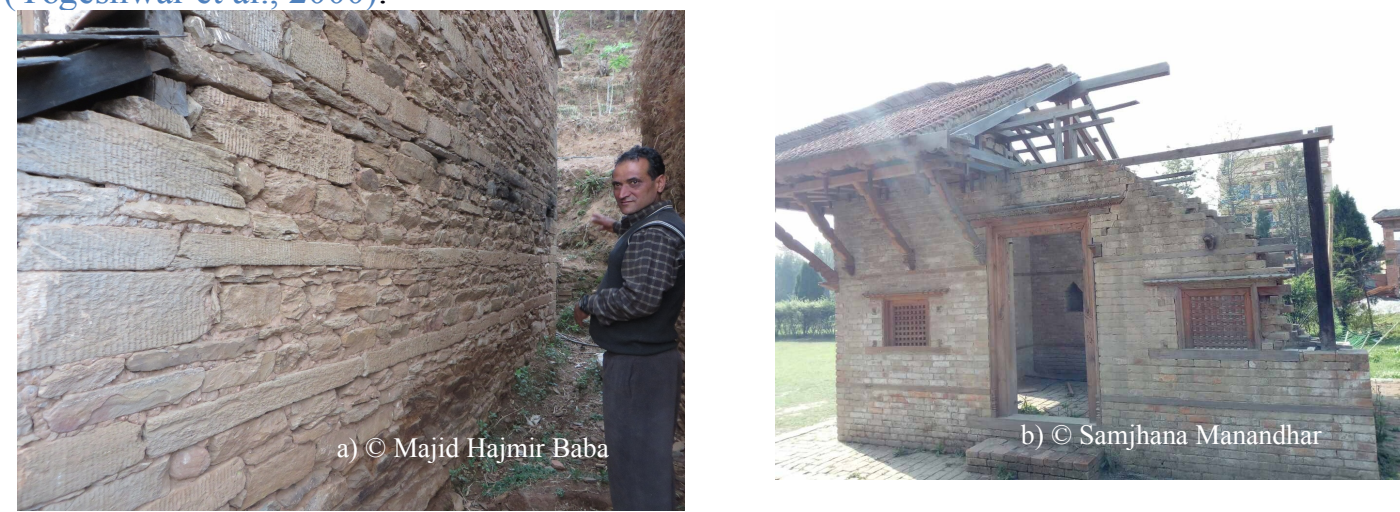

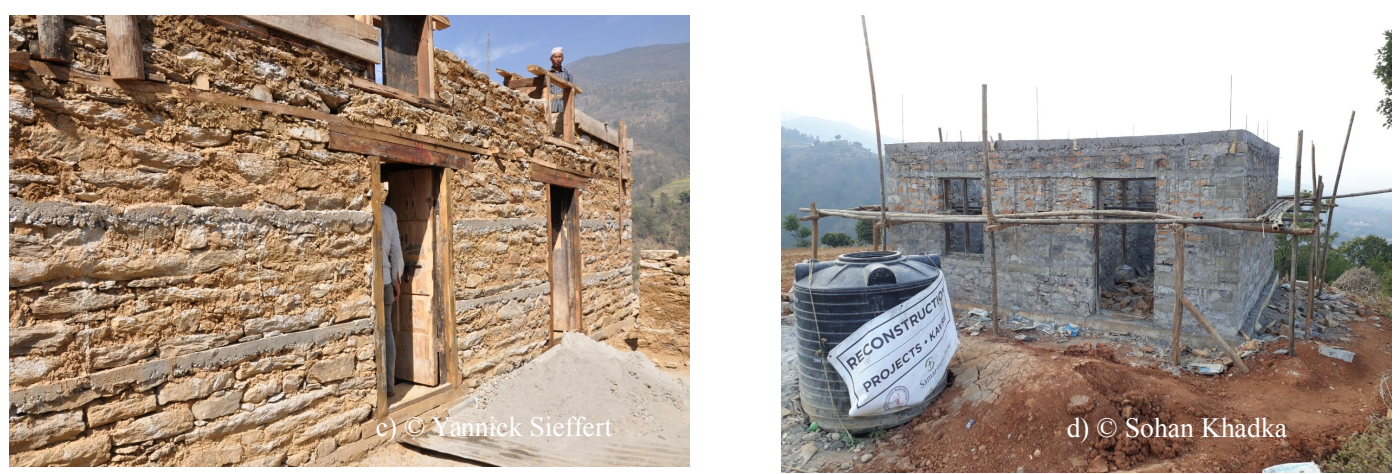

Figure 2. a) Use of stone as a shear band, b) Timber shear band in brick masonry, c) Use of concrete and timber shear band in clay mortar masonry and d) Concrete shear band in cement mortar masonry building

Figure 2 a) shows the use of stones as shear bands in the Gatlang village of Rasuwa District which was constructed before the earthquake in 2015 and resisted well during the seismic action. Similarly, timber shear band used in brick masonry structure can be seen in Banepa as shown in Figure 2 b) where the complete collapse of the roof occurred during 2015 earthquakes, which might be due to the heavy weight of the roof or lack of proper connections between the walls and the roof. After 2015 earthquakes, people started using shear bands as they understood their relevancy as an aseismic feature. Moreover, different NGOs and INGOs have started training masons on properly implementing shear bands. Figure $2 \mathrm{c}$ ) shows the use of concrete and timber shear bands in stone masonry structures with clay mortar in Megapauwa, Dolakha district, and in Figure 2 d), a concrete shear band can be seen in a stone masonry with cement mortar building in Kavrepalanchok district.

\section{Design catalogue for reconstruction:}

The National Building Code regarding masonry and $\mathrm{RC}$ structures was published in 1994. It recommends the use of horizontal bands/ring beams at plinth, lintel, roof, and gable level as a structural reinforcement. But this practice was far too often not implemented due to lack of knowledge among local community and authority (Yogeshwar et al., 2000).

The design catalogue for earthquake resistance guidelines consists of the design specification for simple masonry building with minimum requirements that should be fulfilled for reconstructing buildings that could resist the damage caused by the earthquake in the near future using horizontal shear bands as shown in Figure 3. The main objective of reconstruction housing guidelines is to translate into a concept of safer settlement using the principles of Build Back Better (BBB) (DUDBC, 2015). This design catalogue was prepared to have more efficient approach for reconstruction work with the model design building with one or two storeys. The first design catalogue for reconstruction work has been prepared in a more conservative way by limiting one storey height for masonry with mud mortar however as per the NBC 203, the storey could be up to 2 storeys with an attic. The reason for this could be that people would be in a hurry to reconstruct their building leading to poor quality of work. Therefore, by limiting the single storey height for mud mortar masonry and up to two storeys with cement mortar masonry could ensure the safety of the building. The material for such horizontal shear band could be timber, concrete, or bamboo depending on their availability as per the guidelines. The dimension of the longitudinal timber member is $75 \mathrm{~mm} \times 45 \mathrm{~mm}$ and that for transverse connection is 50 $\mathrm{mm} \times 45 \mathrm{~mm}$, which is placed at a spacing of $600 \mathrm{~mm}$ centre to centre. For cement mortar masonry wall, the mortar should not be leaner than 1:4 (1-part cement, 4-part sand). 

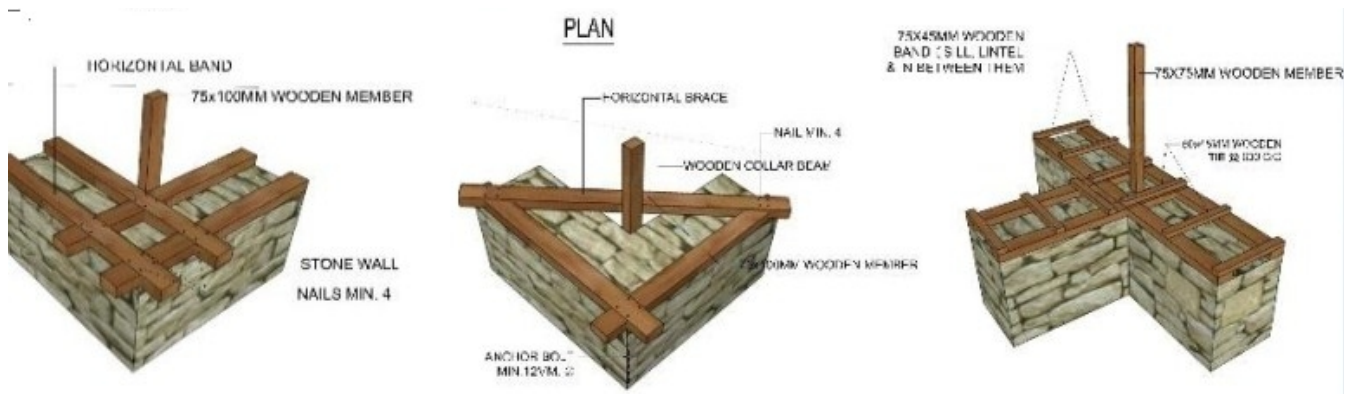

Figure 3. Timber horizontal and vertical band at corner and T-junction

[Source: (DUDBC, 2015)]

For the concrete shear band, the thickness should be minimum $75 \mathrm{~mm}$ for sill, corner stitch, roof, and gable band whereas for plinth and lintel level band; thickness should be minimum 150 $\mathrm{mm}$ with reinforcement bar as shown in Figure 4 below. The concrete mix for the seismic band should not be leaner than 1:1.5:3 (1-part cement, 1.5 parts sand, and 3 parts aggregate).

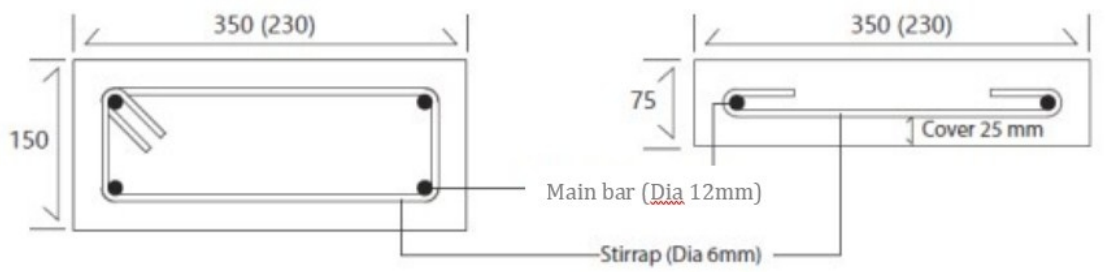

Figure 4. Reinforcement bar detailing for concrete shear band

[Source: (DUDBC, 2015)]

\section{Experimental setup:}

For carrying out the impact of materials used as shear bands, series of experimental tests were performed in cyclic quasi-static loading. The aim of these tests was to apply loading directly on the shear band to analyze the energy dissipation at the interface of the shear bands.

\section{Apparatus and specimen preparation:}

As the first approach, the four types of shear band described in Table 1 were tested (two specimens per types). For timber shear band type 1, one of the specimens was prepared with dry stone masonry between the top and bottom layers of clay mortar, which is referred as TSB1_2_dry in this article. To determine the behaviour of a different type of shear band as practice and proposed in the guideline of Nepal, planning to perform the cyclic shear test on the specimen having dimension $900 \mathrm{~mm} \times 350 \mathrm{~mm}$ with the same detailing for the shear band as prescribed in the guideline (DUDBC, 2015) was made. Most of the houses in the rural part of Nepal are constructed using clay mortar and stone. Thus, to find the response of that masonry structure with the shear band, the eight specimens were planned to be tested using clay mortar, stone, timber, bamboo, and concrete.

Table 1. Different type of shear band used for experiment

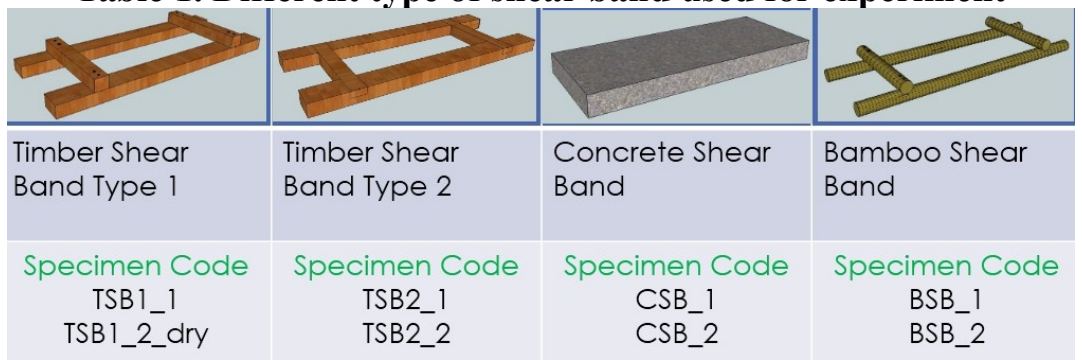


For the preparation of specimens, first, the clay mortar was prepared by adding water and left it for 4-5 days to have proper swelling of clay before using in the specimen. After that, the shear band was prepared using timber and bamboo, and for the concrete shear band, the reinforcement net as per the detail provided in the DUDBC guideline was prepared. For timber shear band type 1 and bamboo, the transverse ties were connected using nails whereas for timber shear band type 2; the notch was created in the main longitudinal section and a transverse member and connected properly as shown in above Table 1 . The dimension of longitudinal timber member was $900 \mathrm{~mm} \times 75 \mathrm{~mm} \times 45 \mathrm{~mm}$, and that of the transverse member was $350 \mathrm{~mm} \times 50 \mathrm{~mm} \times 45 \mathrm{~mm}$. Flow chart as shown in Figure 5 outlines the steps used during the preparation of each specimen.

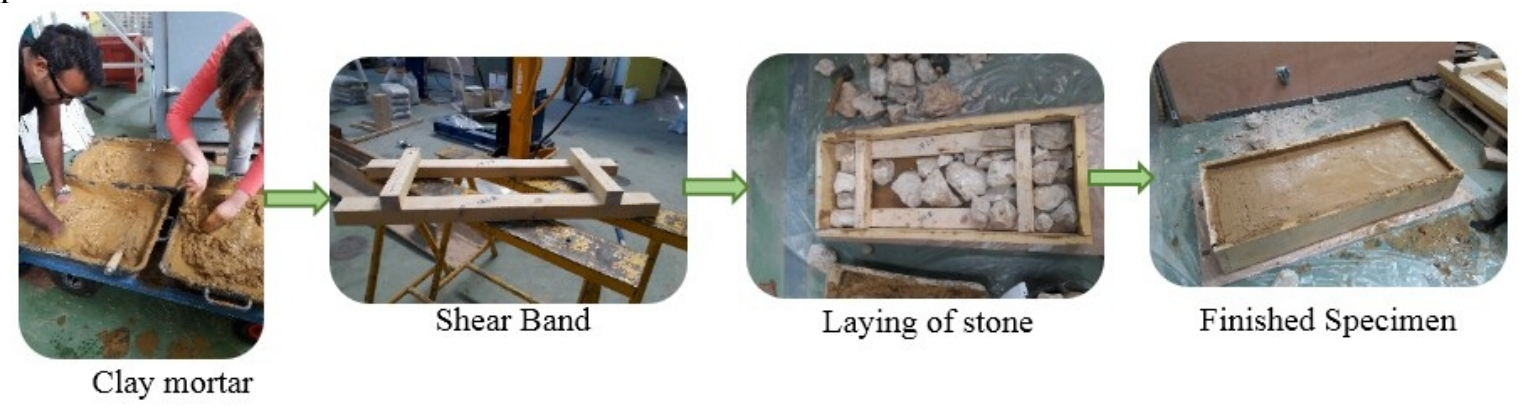

Figure 5. Flow chart for preparation of specimen

For the concrete shear band, a layer of clay mortar with thickness $15 \mathrm{~mm}$ was placed first, and after that, the reinforcement frame net was inserted. The M20 (Compressive Strength $20 \mathrm{MPa}$ ) grade (Bureau of Indian Standard, 1999) of concrete was prepared using 11kg of cement (Type: CEM I, 52.5 Normal [EN 197-1 (2001)]), $19 \mathrm{~kg}$ of fine aggregate and $30 \mathrm{~kg}$ of coarse aggregate with maximum size of $10 \mathrm{~mm}$ for each specimen and poured in the frame. To have good bonding between the clay layers and concrete, some broken stone pieces both on top and on bottom were added while placing concrete. All the specimens were tested in the Schenck machine with the setup as shown in Figure 6 where cyclic loading was applied to the shear band using hydraulic jack. Only translational motion of shear band in vertical direction was allowed and other translational and rotational motions were restricted using steel plate connection as shown Figure 6.

\section{Loading protocol:}

The maximum horizontal displacement due to seismic force between two successive floors should not exceed 0.004 times the difference in levels between the floors (Bureau of Indian Standard, 1986) which makes for single $2.4 \mathrm{~m}$ storey height; the allowable displacement is 9.6 $\mathrm{mm}$ for reinforced concrete building but for masonry structures, the dissipation of energy is allowed by the displacement of elements and their elastic distortion. In order word, the inter storey drift must be less or equal to $0.4 \%$. To set the limit of displacement for the test, the maximum limit of $20 \mathrm{~mm}$ for each specimen was selected except for the first timber shear type 1 specimen that was tested up to $10 \mathrm{~mm}$ displacement to see the behaviour as an interface and confirm that the experimental set up works correctly. For the first specimen with concrete shear band CSB1, with the hypothesis of getting higher resistance to the shear loading, the displacement limit was set to $5,10,15,20$ and $25 \mathrm{~mm}$ but later it was realized that the displacement beyond $20 \mathrm{~mm}$ was not of interest and the remaining specimen were tested with the limit of $20 \mathrm{~mm}$ final displacement limit or until failure. The test was carried out in displacement controlled pattern with displacement limit of 4, 8, 12, 16 and $20 \mathrm{~mm}$ for three cycles at each level in both direction of loading (Vieux-Champagne et al., 2014) as shown in Figure 7. The rate of displacement was $0.4 \mathrm{~mm} / \mathrm{sec}$ for each of the test. 

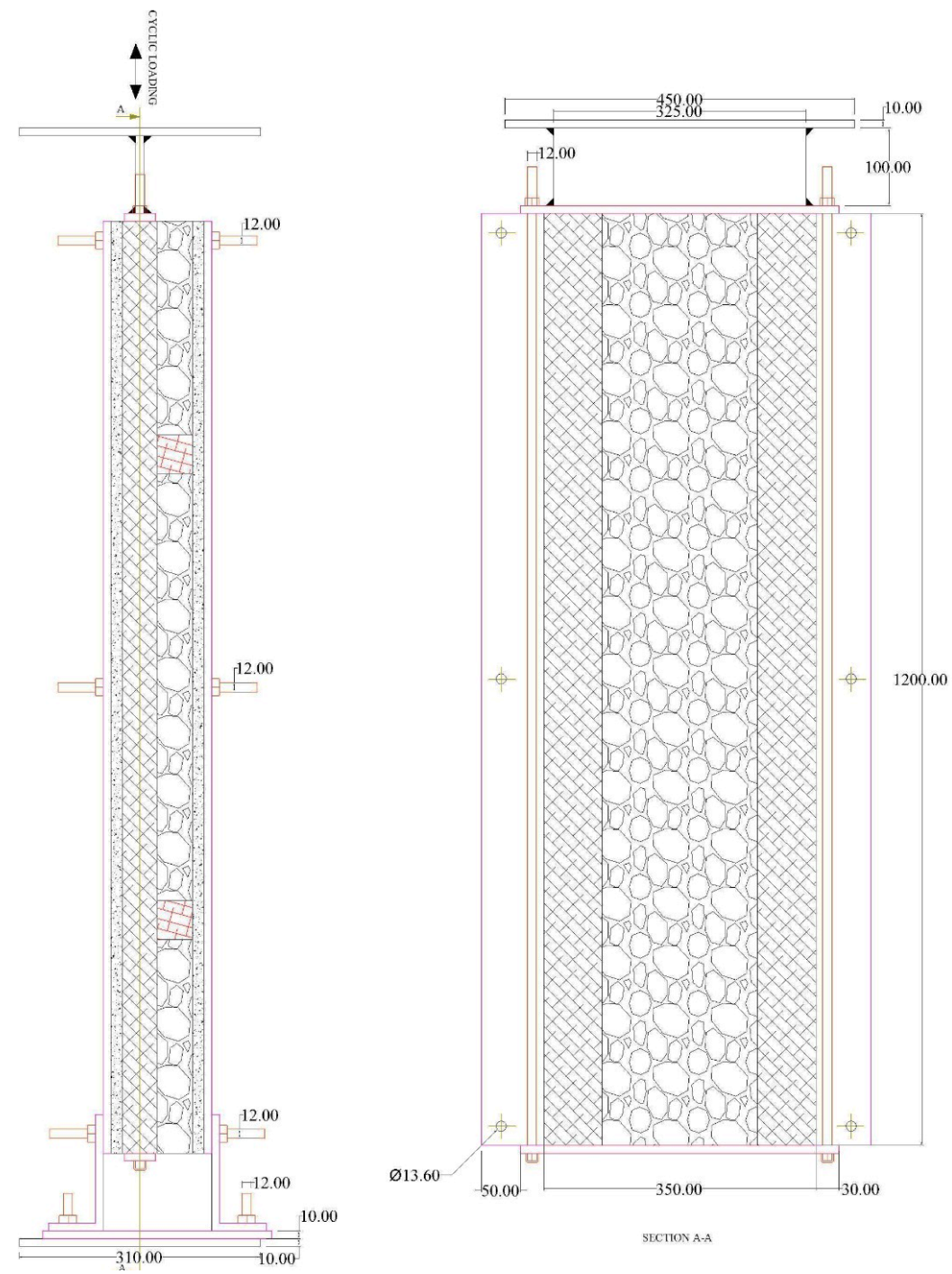

Figure 6. Experimental set up for cyclic shear loading

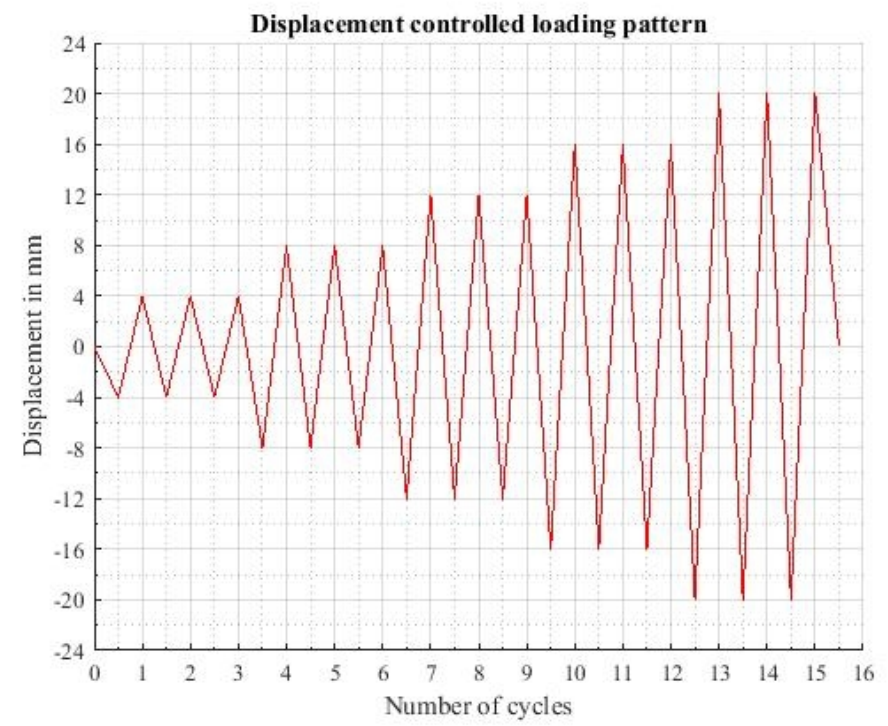

Figure 7. Displacement controlled loading pattern 


\section{Test setup and data acquisition:}

To take into account the pre-compressive load acting at shear band section due to wall above that level along with live load and loading from the roof, the total load has been calculated taking the density of masonry $20.4 \mathrm{kN} / \mathrm{m}^{3}$ and imposed live load of $3 \mathrm{kN} / \mathrm{m}^{2}$ and 0.75 $\mathrm{kN} / \mathrm{m}^{2}$ for sloping roof member with purlins (Bureau of Indian Standard, 1989).

Considering height above sill band $2 \mathrm{~m}$ for single storey building and $4.55 \mathrm{~m}$ for two-storey building, the maximum vertical load, acting at the shear band level has been computed as 15.2 $\mathrm{kN}$ and $33.36 \mathrm{kN}$ respectively. To apply this pre-compression loading on the wall, a metallic plate was used on both sides of the sample with six bolts having $12 \mathrm{~mm}$ diameter. Each bolt was pre-compressed using $20 \mathrm{Nm}$ torque wrench. The pre-compressive force in the bolt comes out to be $8.33 \mathrm{kN}$. With this experiment, the sliding behaviour of the shear band at the interface layer has been observed as shown in Figure 8. The loading head of a hydraulic jack was vertically aligned with the shear band, and the top and bottom plate was connected using long bolt rod without leaving any space between the shear band and connecting plate. Hence, the displacement records for the jack head and force applied were recorded and stored in an Excelbased format, which were further used in analyzing the results.
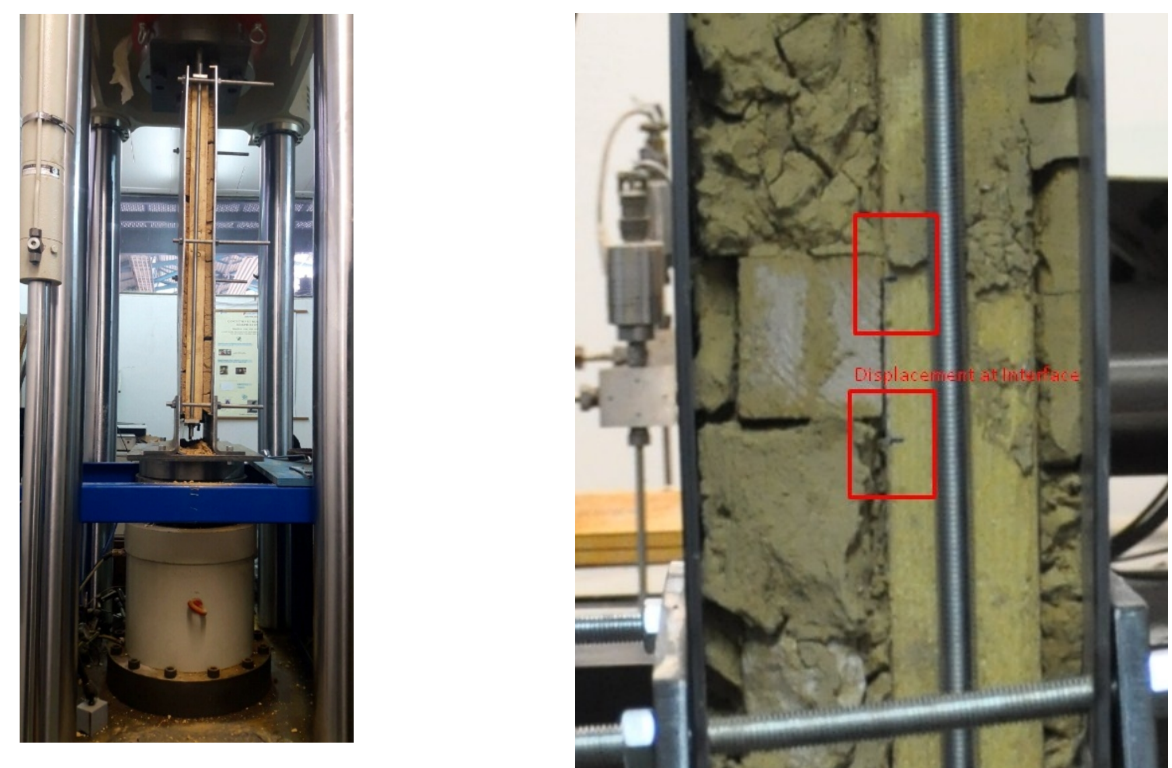

Figure 8. Experimental setup (left) and displacement at the interface between shear band and mortar layer (right)

\section{Results \& discussion:}

\section{Experimental findings:}

Reproducibility of the sample is a critical component to finding the precision of measurement and test method. To have more accurate reproducibility result, many specimens must be tested. For a preliminary step towards achieving global goal, testing of two specimens for each type of shear band were carried out as explained above.

The result in Figure 9 shows the comparison of the hysteresis curve of two specimens of timber shear band type 1. At small displacement up to $4 \mathrm{~mm}$, the first specimen seems to provide more shear resistance, which may be due to adhesive bonding between stone and clay however it can be observed from the plot that for dry stone beyond $8 \mathrm{~mm}$ displacement, the hysteresis loops become bigger resulting in more energy dissipation. 
For timber shear band type 2 with the transverse tie connected by making a notch, higher shear resistance was observed as shown in Figure 10. The maximum shear force in the negative loading zone is higher than the positive loading zone that is because the beginning of each range of displacement cycle was started from negative loading. The two curves for same type of shear band have similar pattern of loading and displacement thus, the reproducibility of the sample was met up to some extent however a number of specimens is required to be tested for calculation of a mean and standard deviation. Likewise, the result for Timber SB2_1 is only up to $16 \mathrm{~mm}$ which is due to the problem that the loading plate was about to touch the metallic plate of experimental setup while performing the test and the test was stopped beyond that limit.

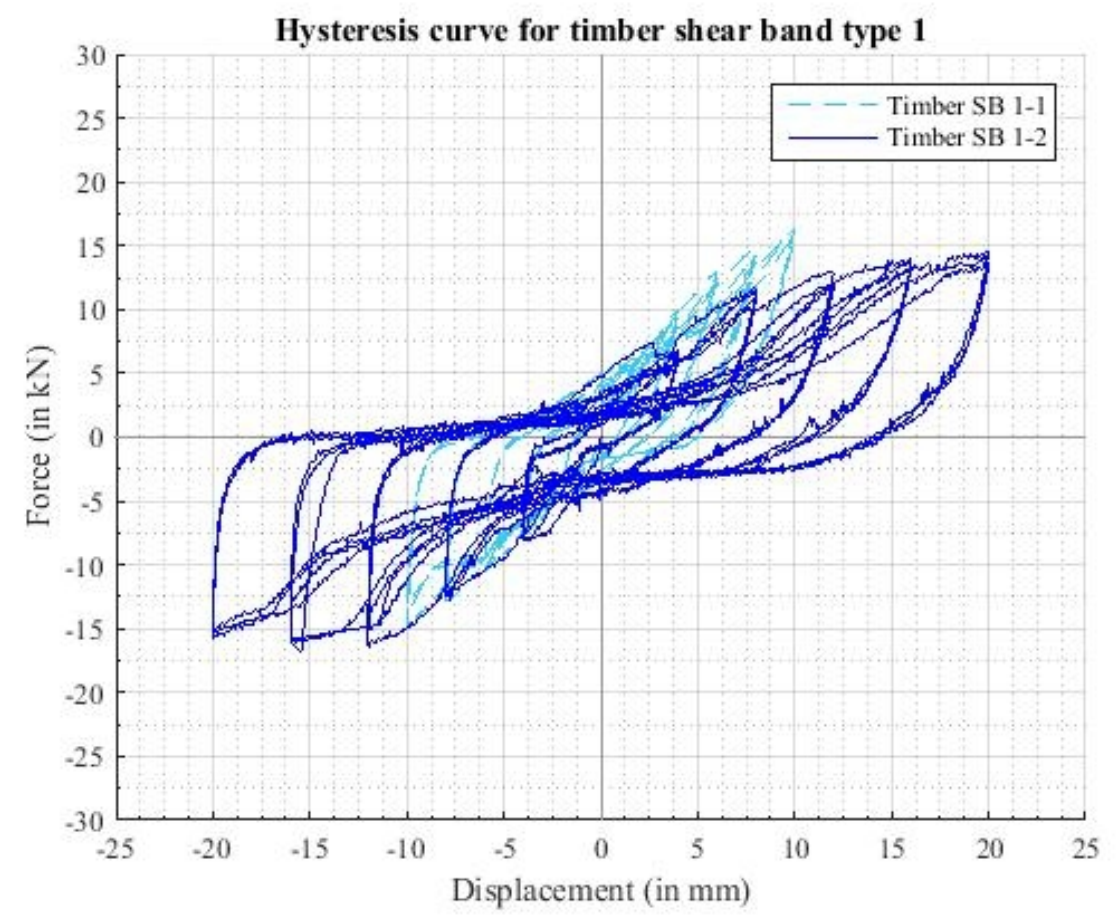

Figure 9 Hysteresis curve for timber shear band type 1

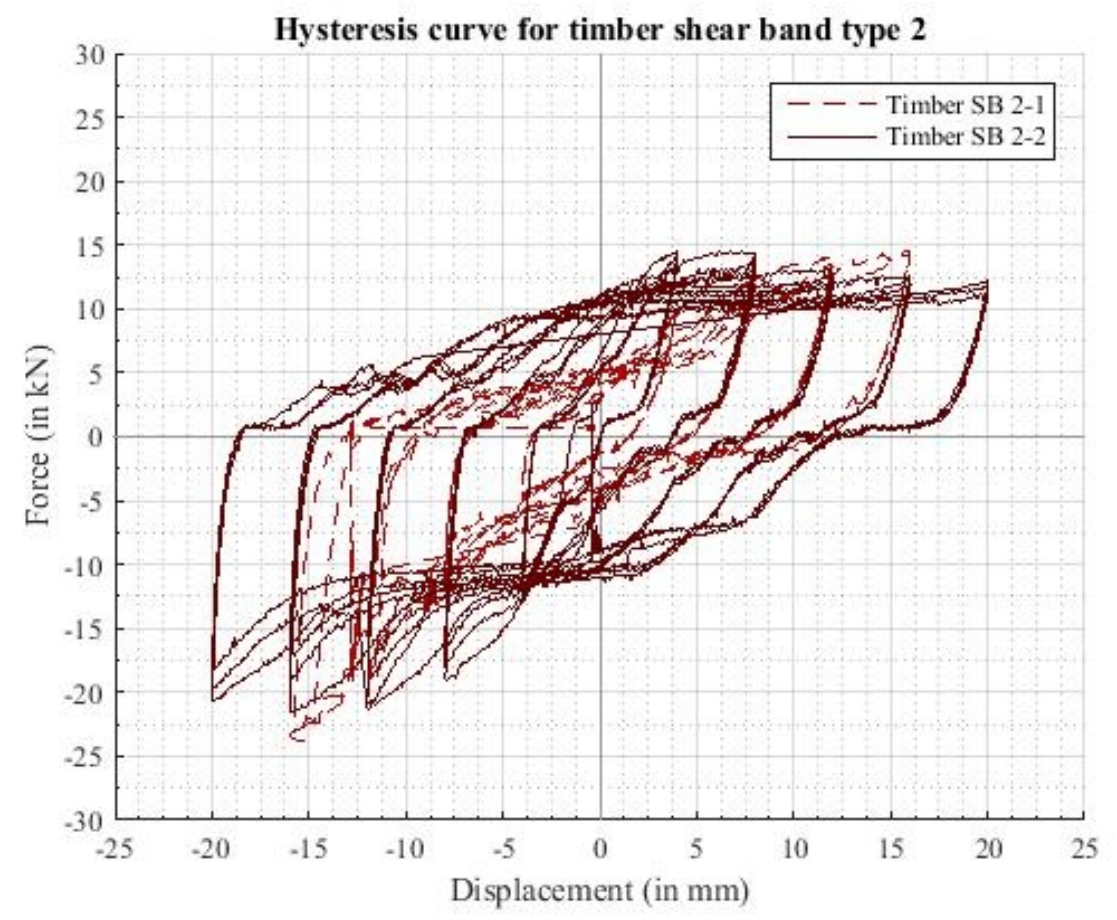

Figure 10 Hysteresis curve for timber shear band type 2 
For proper bonding between concrete and clay mortar layer, few pieces of stone were used while placing concrete. As shown in the Figure 11, there is sliding behaviour observed both in positive and negative loading zone around $10 \mathrm{kN}$ force which means at this level of loading the frictional resistance between the clay and concrete is broken down. The remaining load is carried on by the connecting stone between two layers which determines the extra loading capacity of the band which might be the reason for the different pattern of hysteresis loop as the number and size of stones were not exactly the same in two specimens with concrete SB. The nature of hysteresis loop which is wide resulting in more dissipation of energy can be observed in the plot. Also, in the case of bamboo shear (Figure 12), the hysteresis loop is thinner and comparable in both the specimen addressing the reproducibility requirement for validation of test method and results obtained.

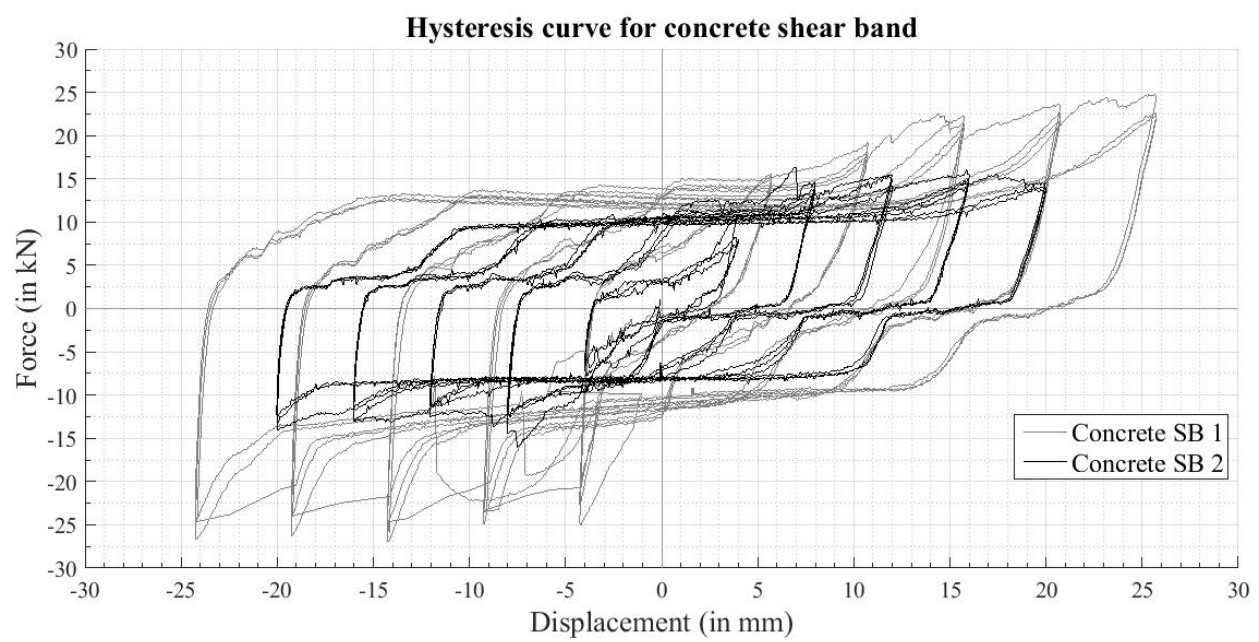

Figure 11 Hysteresis curve for concrete shear band

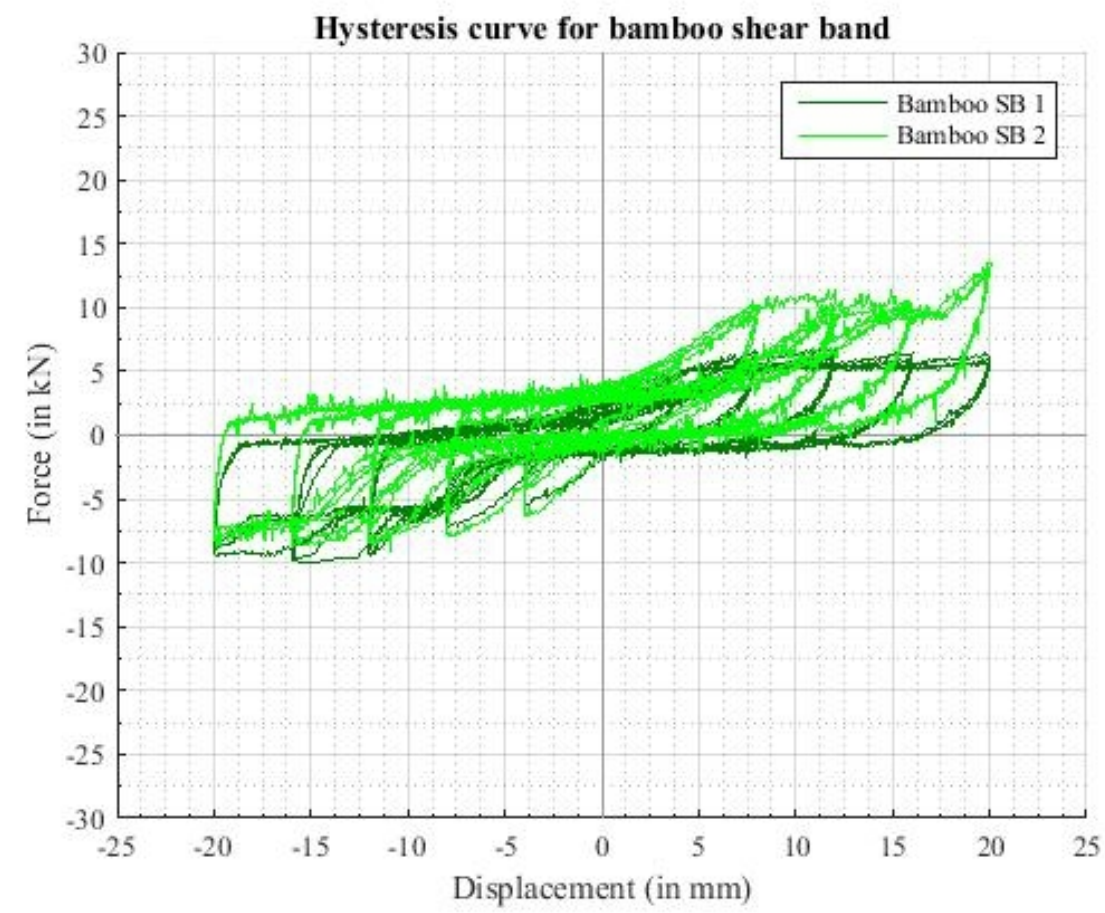

Figure 12 Hysteresis curve for bamboo shear band

While making a comparison between timber shear band type 1 and 2 as shown in Figure 13, SB type 1 has narrow hysteresis loop as compared to type 2 . The reason could be due to the 
connection of transverse ties using a nail in the case of type 1 which is easily bent and shifted with loading. Similarly, the curve with type 1 is symmetric which could be due to the equal force needed for bending of the nail connection (Figure 14) in both direction allowing similar displacement whereas with type 2, the loading in the compression zone that is on negative loading side is more than in the tension zone which could be due to the connection type which breaks during first compression cycle at each level of displacement. For timber SB type 2, the connection between the timber pieces is rigid that the stones which are in contact with the transverse member are also displaced. For the first cycle of displacement, there is friction resistance between shear band and mortar as well as the static resistive force from the stone layer in contact with transverse member and hence, more force is required to overcome it, but once the stones are displaced, it is easier to displace it after and less force for the following cycles.

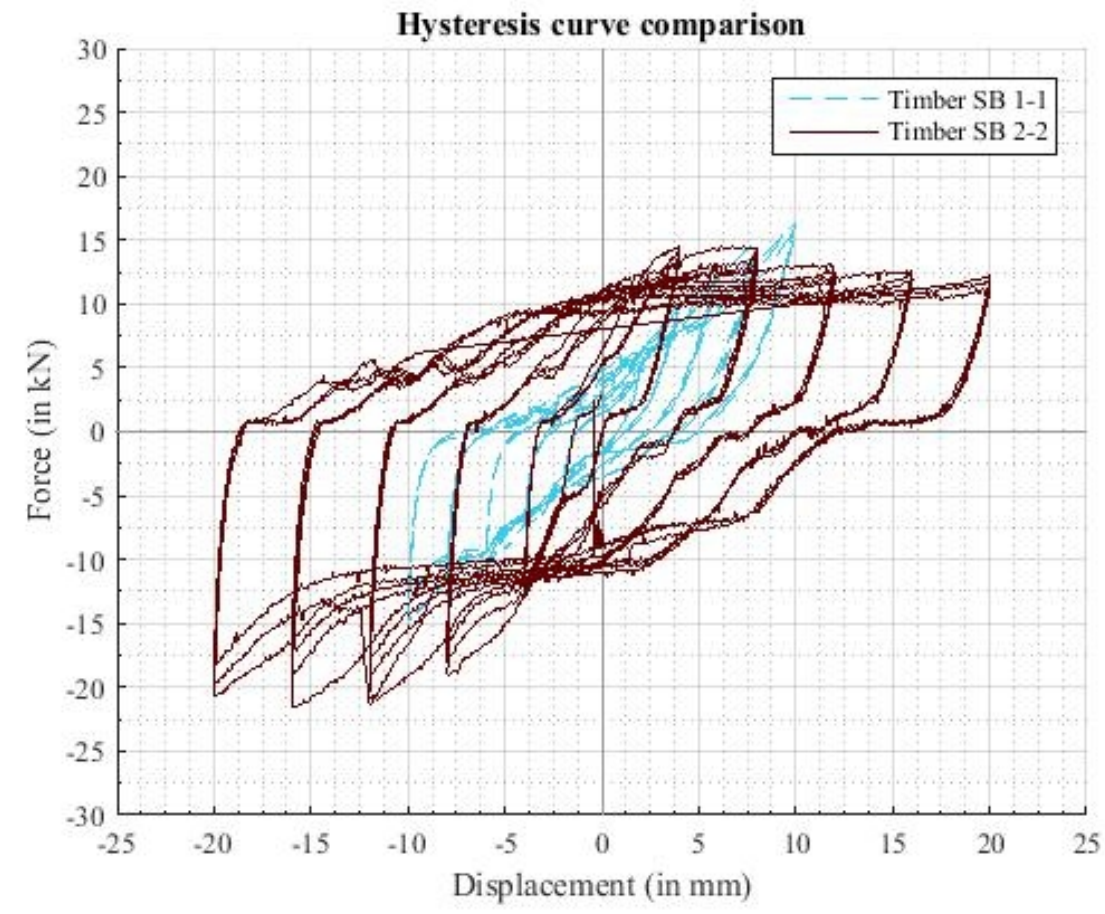

Figure 13. Comparison between timber Shear Band Type $1 \& 2$

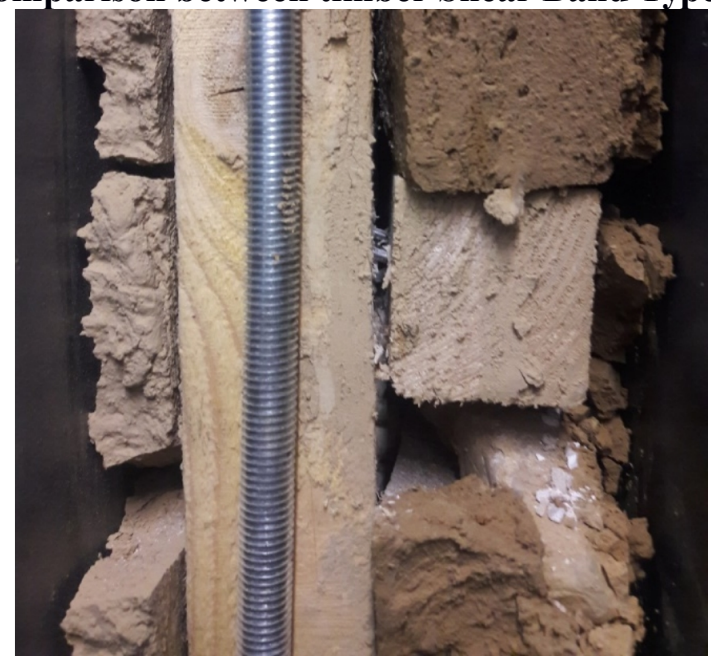

Figure 14. Bending of nail connection in timber SB type 1 specimen

While comparing the concrete SB2 with timber SB1_2_dry in Figure 15, the maximum shear load carrying capacity in case of timber is lower than in concrete and so is the nature for dissipation of energy. The reason for concrete shear band dissipating more energy could be the 
more surface area is in contact with the clay layer creating a more frictional loss of energy. In case of bamboo, there is sudden sliding behaviour observed at low shearing load and the hysteresis loop is also thinner as compared to timber shear band as shown in Figure 16.

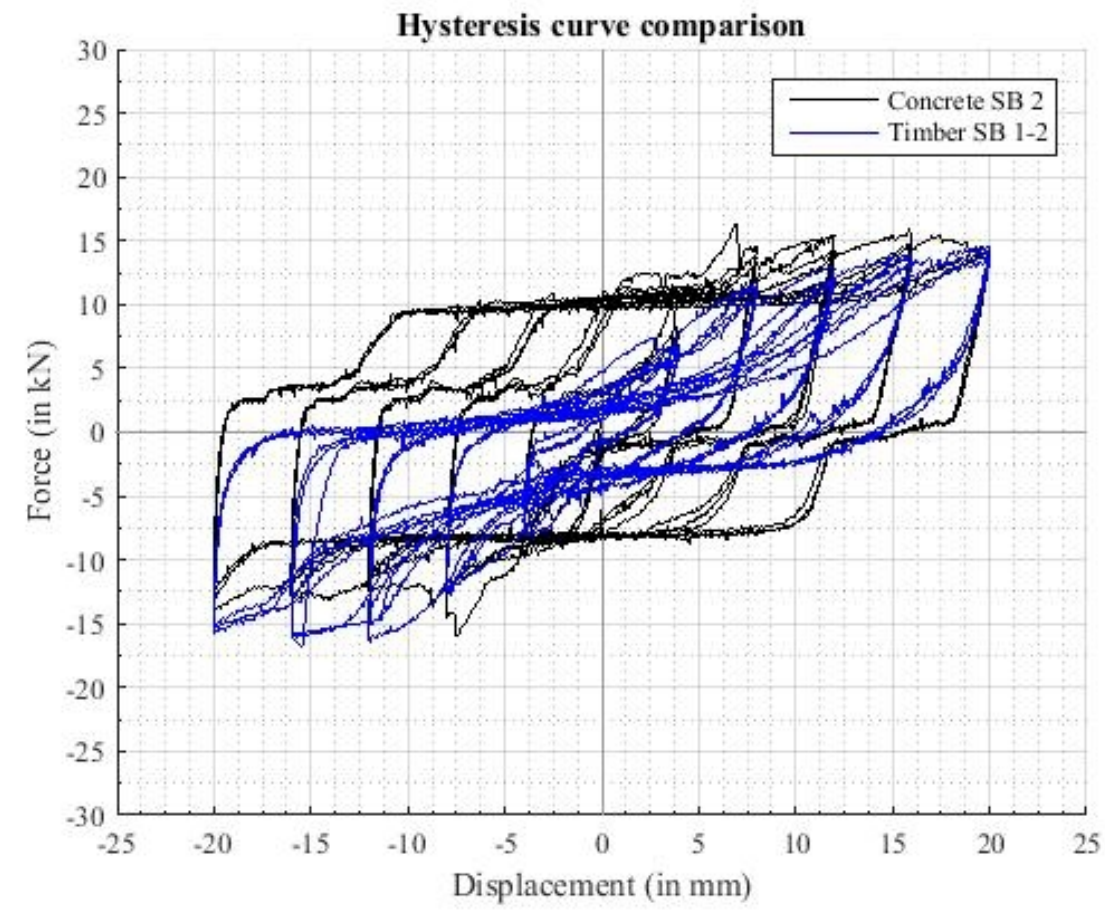

Figure 15 Hysteresis curve comparison of concrete SB with timber SB1_2_dry

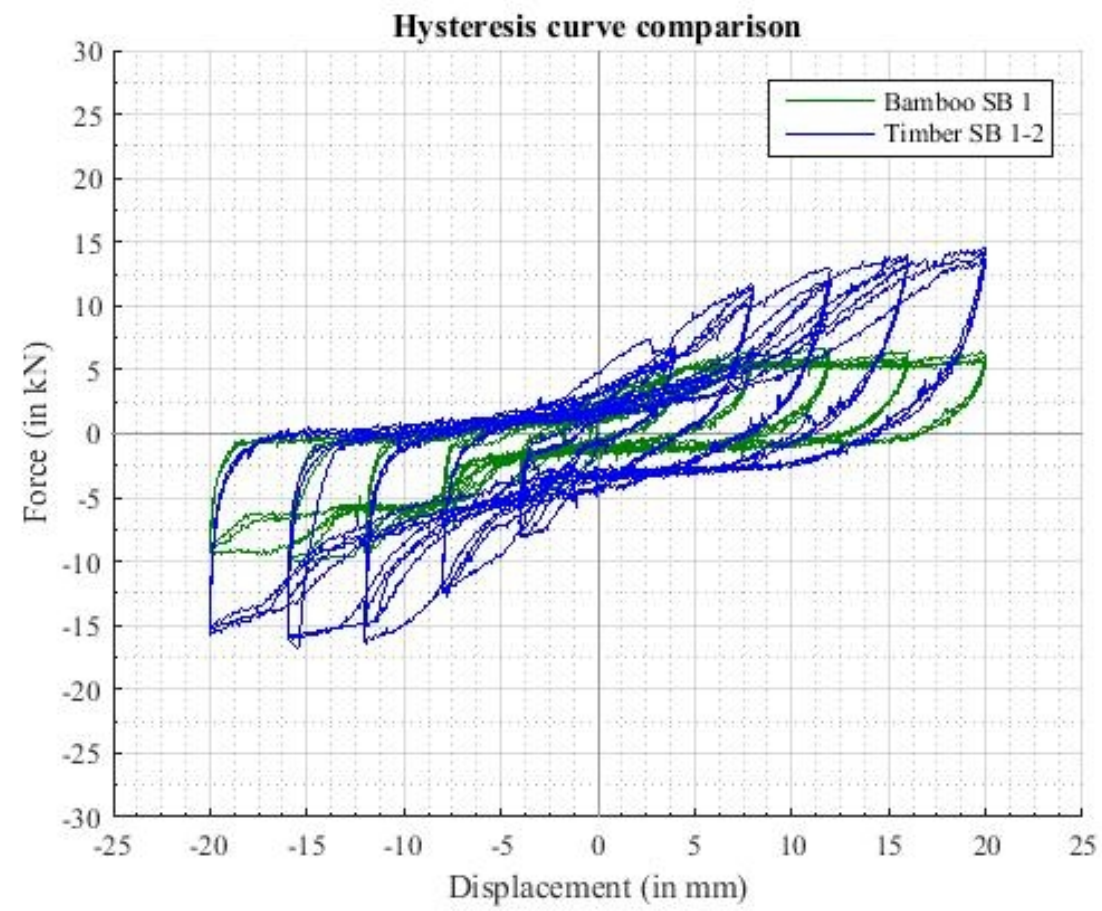

Figure 16 Hysteresis curve comparison of bamboo SB with timber SB1_2_dry 
Dissipation of energy:

One of the use of shear band is to limit the propagation of a crack in the wall, confine all the wall together and dissipate energy by sliding friction caused during seismic action. For this purpose, the amount of energy dissipated by each cycle upon particular displacement was measured from the previous hysteresis loop curve using OriginPro 2017 software (http://www.originlab.com/2017) and taking the average between the results obtained from the similar type of shear band connection. Comparison of energy dissipation by various type of shear band is shown in Figure 17. From the comparison, it is observed that more energy is dissipated with Concrete SB as compared to other material and least energy is being dissipated by Bamboo SB. There is also a difference in the amount of energy dissipated with a different type of connection using timber as a shear band. Timber Shear Band type 2 (TSB2) could dissipate more energy than Timber Shear Band type 1 (TSB1). In order to observe the significance of the contact surface area, the results for the concrete and bamboo SB was normalized as that of timber shear band and as seen in the same plot, the energy dissipated by the normalized CSB and normalized BSB are just close enough to that of TSB1. The energy dissipation patterns obtained tend to follow linear form for each of the shear band material.

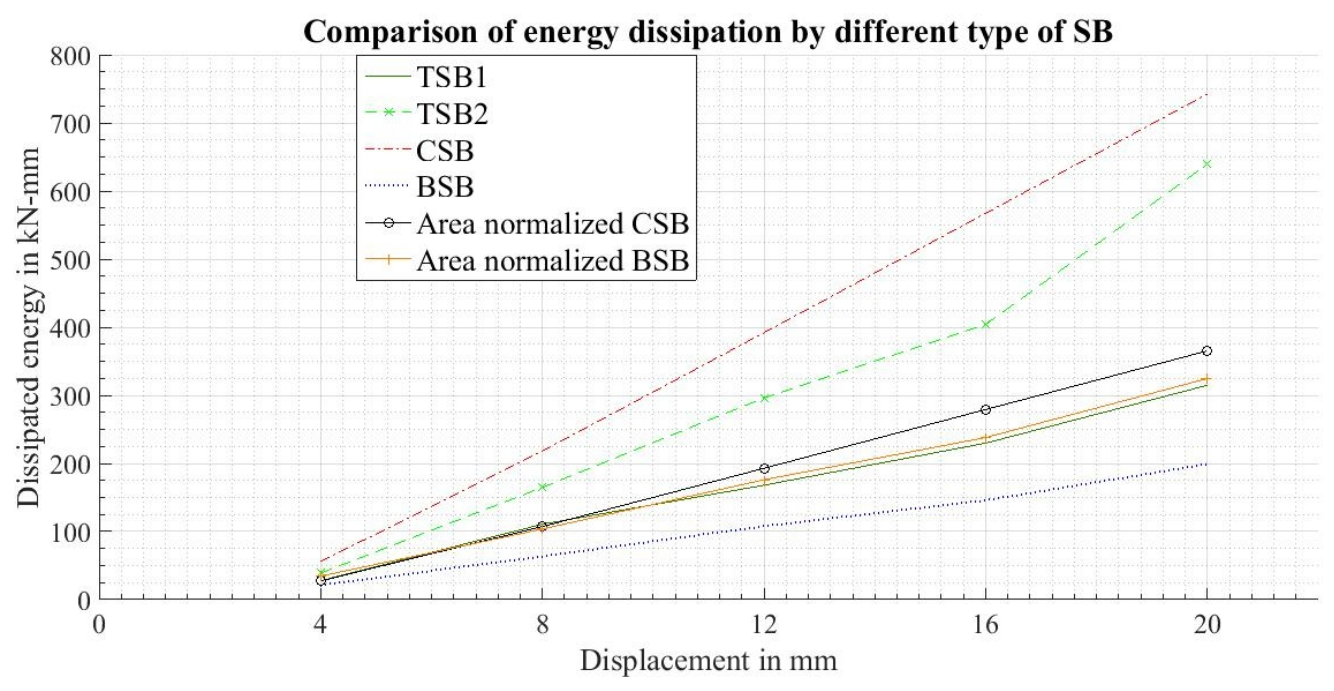

Figure 17. Comparison of energy dissipation by different types of SB

Effective Stiffness and Shear Stress:

For calculation of effective stiffness against sliding for all the types of shear band that were tested, the first loading in compression was neglected until it reached the maximum displacement as defined in the displacement pattern because there might have been some mechanical adjustment during first loading and considered a loop from the first compression to tension values and from tension to compression loading again. After separating the results for each of the loops, linear regression was done to obtain gradient and intercept for the best fitting curve. The gradients obtained are the effective stiffness of shear band against sliding for each specimen as given in Table 2. Likewise, the elastic limit of loading and the corresponding displacement, energy dissipated within elastic limit and maximum energy dissipated was obtained (Table 2) from the hysteresis loop as explained earlier. Similarly, the maximum load carried by each of the specimen while loading in both directions were noted and shear stress was calculated and tabulated in Table 3 below. As observed in the tabular value, the average stiffness and the plastic energy dissipated (which could be use as information about ductility behaviour) of TSB type 2 and concrete SB are comparable, and that of bamboo is the least which means a small amount of force can make large displacement with bamboo used as a shear band. These values of stiffness and energy dissipated can be used in development and validation of numerical simulation code for carrying out the parametric analysis for shear band using different material. 
Table 2 Effective Stiffness against Sliding, energy dissipated

\begin{tabular}{|c|c|c|c|c|c|c|c|}
\hline \multirow[b]{2}{*}{ S.No } & \multirow[b]{2}{*}{$\begin{array}{c}\text { Name of } \\
\text { specimens }\end{array}$} & \multicolumn{2}{|r|}{ Elastic } & \multirow[b]{2}{*}{$\begin{array}{c}\text { Effective } \\
\text { Stiffness, } \\
\text { k (N/m) }\end{array}$} & \multicolumn{3}{|c|}{ Energy dissipated } \\
\hline & & $\begin{array}{c}\text { Force, } \\
\text { kN }\end{array}$ & $\begin{array}{c}\text { Displacement, } \\
\text { mm }\end{array}$ & & $\begin{array}{l}\text { Elastic, } \\
\text { kN-mm }\end{array}$ & $\begin{array}{l}\text { Maximum, } \\
\text { kN-mm }\end{array}$ & $\begin{array}{l}\text { Plastic, } \\
\text { kN-mm }\end{array}$ \\
\hline 1 & TSB1_1 & 12.4 & 6.3 & $1.61 \mathrm{E}+06$ & 75.32 & 109.5 & 34.18 \\
\hline 2 & TSB1_2_dry & 11.45 & 8 & $1.33 \mathrm{E}+06$ & 112.3 & 314.76 & 200.46 \\
\hline 3 & TSB2_1 & 10.78 & 8.08 & $1.35 \mathrm{E}+06$ & 167.46 & 298.9 & 131.44 \\
\hline 4 & TSB2_2 & 14 & 7.87 & $2.61 \mathrm{E}+06$ & 201.53 & 639.5 & 437.97 \\
\hline 5 & CSB_1 & 18.09 & 10.95 & $2.63 \mathrm{E}+06$ & 406.25 & 877.71 & 471.46 \\
\hline 6 & CSB_2 & 13.15 & 7.9 & $1.21 \mathrm{E}+06$ & 180.67 & 607.07 & 426.40 \\
\hline 7 & BSB_1 & 6.25 & 8.22 & $6.19 \mathrm{E}+05$ & 56.28 & 200.7 & 144.42 \\
\hline 8 & BSB_2 & 6.23 & 7.9 & $8.90 \mathrm{E}+05$ & 72.11 & 197.26 & 125.15 \\
\hline
\end{tabular}

Table 3 Maximum load carried and shear stress during cyclic loading

\begin{tabular}{|c|c|c|c|c|c|c|c|}
\hline \multirow[b]{2}{*}{ S.No. } & \multirow[b]{2}{*}{$\begin{array}{l}\text { Name of } \\
\text { specimens }\end{array}$} & \multicolumn{2}{|c|}{ Downward direction } & \multicolumn{2}{|c|}{ Upward direction } & \multicolumn{2}{|c|}{ Shear Stress, kN/m² } \\
\hline & & $\begin{array}{c}\text { Max } \\
\text { Force, } \\
\text { kN }\end{array}$ & $\begin{array}{l}\text { Displacement, } \\
\text { mm }\end{array}$ & $\begin{array}{c}\text { Max } \\
\text { Force, } \\
\text { kN }\end{array}$ & $\begin{array}{c}\text { Displacement, } \\
\mathbf{m m}\end{array}$ & $\begin{array}{l}\text { Downward } \\
\text { direction }\end{array}$ & $\begin{array}{l}\text { Upward } \\
\text { direction }\end{array}$ \\
\hline 1 & TSB1_1 & 14.70 & 9.95 & 16.32 & 9.95 & 94.84 & 105.29 \\
\hline 2 & TSB1_2_dry & 16.76 & 15.45 & 14.52 & 19.9 & 108.13 & 93.68 \\
\hline 3 & TSB2_1 & 23.90 & 15.30 & 14.57 & 15.78 & 154.19 & 94.00 \\
\hline 4 & TSB2_2 & 21.60 & 15.93 & 14.60 & 6.75 & 139.35 & 94.19 \\
\hline 5 & CSB_1 & 26.93 & 14.23 & 24.77 & 25.67 & 85.49 & 78.63 \\
\hline 6 & CSB_2 & 16.02 & 7.51 & 16.28 & 6.91 & 50.86 & 51.68 \\
\hline 7 & BSB_1 & 9.98 & 14.92 & 6.72 & 11.65 & 105.05 & 70.74 \\
\hline 8 & BSB_2 & 12.30 & 14.84 & 6.74 & 11.64 & 129.47 & 70.95 \\
\hline
\end{tabular}

\section{Cost aspect:}

In order to conduct a financial analysis of construction works of similar types of building in different affected districts of Nepal, a model with two and a half storey houses - which includes an attic that is used as a storage place - was chosen with mud mortar as guided in the Nepal National Building Code 203and the dimension of the building was taken from the design catalogue developed by DUDBC. The detailed quantity of work and a bill of quantities were calculated to get the total cost of construction. The cost of construction ranges from $€ 17,000$ up to $€ 22,000$ (to compare with the state subsidies of $€ 2727$ ). From the field construction work carried out by CRAterre in Dhading district, the cost for reconstruction was approximately $€$ 15,000 with timber shear bands which corresponds with the theoretical cost estimation. The design catalogue for reconstruction and NBC has provision of using shear band using timber, concrete and bamboo, so the cost of only shear band when different material is used has been calculated for each affected district, which is given in Figure 18. The cost of bamboo is way cheaper than timber and concrete shear band. The cost of timber and concrete shear bands highly depends on the material and labour costs at each district. In Dhading and Okhaldhunga district, the cost of timber is cheaper when compared to other districts. Besides, fine and coarse aggregates are cheaper in Sindhuli and Okhaldhunga, which decreases the total cost of the 
concrete shear band. The main reason of the variation in the price of material and labour cost in different districts is their availability. The unit cost is decided by the local authority of the Government along with the representative from suppliers and consumers.

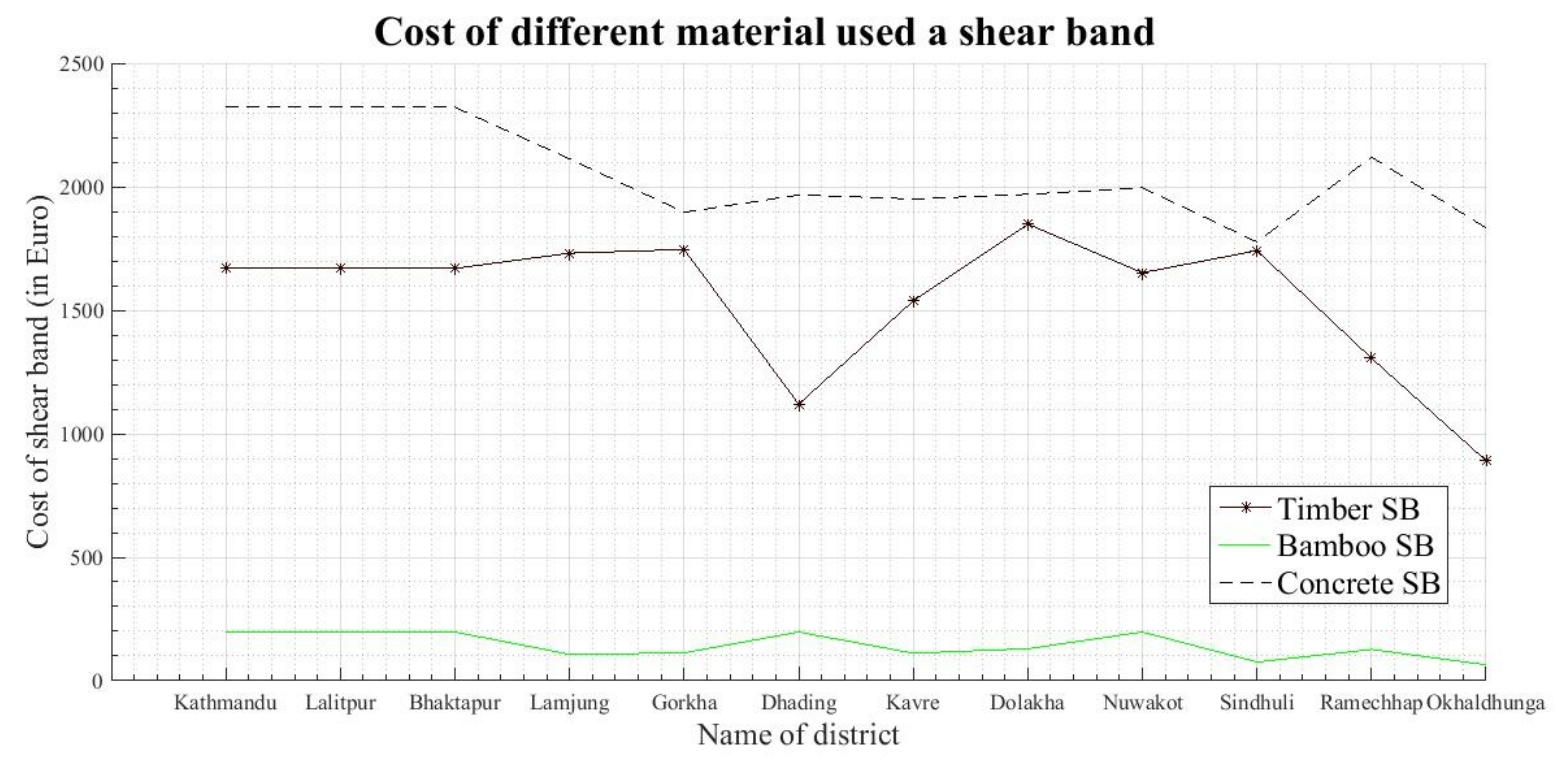

Figure 18. Comparison of Different material used as Shear band

\section{Conclusion and recommendation:}

\section{Conclusions:}

(1) Most of the masonry houses built in rural part of Nepal did not have seismic shear band even though it was already mentioned in the national building code of Nepal which highlights the lack of proper education and implementation of law resulting in huge damage of life and property during Gorkha Earthquake 2015. People started reconstruction works by themselves by implementing seismic shear bands, but due to lack of proper supervision by a trained person, they are not always able to make the shear band correctly.

(2) Regarding the shear bands, various materials are mentioned in the design catalogue and national building code such as timber, concrete and bamboo, but their availability is the main concern in different districts of Nepal even though effort from GoN has been made to facilitate the access to the resources needed for reconstruction works.

(3) Timber shear band type 2 with notched transverse ties has better response property for shear loading as obtained from the experimental results regarding the energy dissipated, nearly twice as much as type 1 . Moreover, type 2 is probably much more resistant also regarding out-of-plane solicitation of the wall and the prevention of wall delamination.

(4) The energy dissipation by the concrete shear band was highest among other materials because of the larger surface area of contact. However, the cost of the concrete shear band is higher than that of timber except for few districts where they cost almost similar.

(5) The use of bamboo as a shear band provides the least dissipation of energy and poor response to the shear loading as there is sliding phenomenon appearing quite fast and the contact area is small. The connection of bamboo using nail is not very stable, and it can easily be dislocated during construction handling. However, bamboo is very cheap and 
further research should be conducted to improve the roughness of the bamboo or its surface area, for example by crushing it before using it in a shear band.

(6) The cost of the reconstruction of new houses is high for the majority of people living in the rural regions, but if materials like timber and stones are re-used from the previously damaged building, it can be completed at low cost. So, to make reconstruction works more efficient and economical, people should be encouraged to utilize their own resources available rather than going for new materials.

(7) Skilled manpower is essential for construction and maintenance works and tolerance limit for a bad execution of construction works should be fixed by the authorized organization.

(8) As a first approach towards this type of experiment with shear bands, there were some difficulties faced which could be rectified and perform more precise experiments for better accuracy. Further research work could be performed for improvement technique for rugosity of the bamboo surface, varying the dimension of concrete and timber shear bands to optimize the cost with better seismic performance.

\section{Acknowledgement:}

The authors would like to thank and acknowledge the University of Grenoble Alpes for its support with the AGIR-PEPS 2016 programme (Alpes Grenoble Innovation Recherche Programme Exploratoire Premier Soutien).

This work has been realised in the framework of the LABEX AE\&CC and the IDEX CDP Risk@Univ. Grenoble Alpes as part of the program "Investissements d'Avenir" overseen by the French National Research Agency (reference: ANR-15-IDEX-02).

\section{References:}

Arya, A. S., Boen, T., \& Ishiyama, Y. (2013). Guidelines for Earthquake Resistant NonEngineered Construction. Paris, France: UNESCO.

Bothara, J., \& Brzev, S. (2011). A Tutorial: Improving the Seismic Performance of Stone Masonry Buildings.

Bureau of Indian Standard. IS 1893-1984 Criteria for Earthquake Resistant Design of Structures, $2405 \S$ (1986). India.

Bureau of Indian Standard. Code of Practice for Design Loads ( Other Than Earthquake ) for Buildings and Structures, 875 BIS § (1989). India.

Bureau of Indian Standard. Recommended Guidelines for Concrete Mix Design (1999). India.

Choudhury, T., Milani, G., \& Kaushik, H. B. (2015). Comprehensive numerical approaches for the design and safety assessment of masonry buildings retrofitted with steel bands in developing countries: The case of India. Construction and Building Materials, 85, 227246. https://doi.org/10.1016/j.conbuildmat.2015.02.082

DUDBC. (2015). Design Catalogue for Reconstruction of Earthquake Resistant Houses (Vol. 1). Kathmandu.

Ferrigni, F., Helly, B., Mendes Victor, L., Pierotti, P., Rideaud, A., \& Teves Costa, P. (2005). The Local Seismic Culture Approach: principles, methods, potentialities. In Ancient Buildings and Earthquake. Ravello: Centro universitario europeo per i beni culturali, Edipuglia srl.

Foundation, T. A. (2016). Nepal Government Distribution of Earthquake Reconstruction Cash Grants for Private Houses. The Asia Foundation. San Francisco, USA.

Garnier, P., Moles, O., Caimi, A., Gandreau, D., \& Hofmann, M. (2013). Natural hazards, disasters and local development. CRAterre. Retrieved from https://hal.archivesouvertes.fr/hal-00952809/document 
Goldberg, E. (2015, September 3). Nepal Hasn’t Spent Any Of The \$4 Billion since Earthquake. IMPACT, The Huffington Post. Kathmandu. Retrieved from

http://www.huffingtonpost.com/entry/nepal-hasnt-spent-any-of-the-4-billion-in-donationssince-earthquake_us_55e74a6ee4b0c818f61a486e

Hofmann, M. (2015). Le facteur séisme dans l'architecture vernaculaire. Un décryptage entre déterminants culturels, types de structures et ressources cognitives parasismiques.

James, D. (2016, April 18). Natural disasters since 1900: over 8 million deaths, 7 trillion US dollars. Science Daily. Karlsruhe Institute of Technology. Retrieved from https://www.sciencedaily.com/releases/2016/04/160418092043.htm

Kramer, S. L. (1996). Geotechnical Earthquake Engineering. New Jersey: Prentice Hall.

Langenbach, R. (2000). Intuition from the Past: What We can Learn from Traditional Construction in Seismic Areas. Orta, Turkey.

Langenbach, R. (2009). Preserving the Earthquake Resistant Vernacular Architecture of Kashmir. In Don 't Tear it Down! (pp. 59-61). New Delhi: UNESCO.

Langenbach, R. (2015). Reconstructing Rural Stone Houses in Nepal after the 2015 Earthquake.

Mendes, M. F. (2015). Support to the Swiss Red Cross for reconstruction in Nepal-Field Mission Report. CRAterre. Grenoble.

Milani, G., Milani, E., \& Tralli, A. (2010). Approximate limit analysis of full scale FRPreinforced masonry buildings through a $3 \mathrm{D}$ homogenized FE package. Composite Structures, 92(4), 918-935. https://doi.org/10.1016/j.compstruct.2009.09.037

Milani, G., Shehu, R., \& Valente, M. (2017). Seismic Vulnerability Reduction of Masonry Churches: A case study. Procedia Engineering, 199, 272-277. https://doi.org/10.1016/j.proeng.2017.09.026

Minke, G. (2001). Construction manual for earthquake-resistant houses built of earth. Building Advisory Service and Information Network. Eschborn. Retrieved from http://cd3wd.com/cd3wd_40/GTZCRYS3/h4257e.pdf

National Emergency Operation Center. (2015). Updated report of effects due to disaster events. Retrieved January 1, 2017, from http://drrportal.gov.np/reports

Nepal National Building Code, NBC 202: Mandatory Rules of Thumb Load Bearing Masonry (1994). Nepal: Government of Nepal.

Nepal National Building Code, NBC 204: Guidelines for Earthquake Resistant Building Construction-Earthen Building (EB) (1994). Nepal: Government of Nepal.

Nougaret, A., \& Danuwar, R. P. (2016). Housing, Land and Property issues in Nepal and their consequences for the post-earthquake reconstruction process. CARE Nepal. Kathmandu, Nepal.

NSET-Nepal. (2012). Recorded Historical Earthquakes in Nepal (Earthquake Catalogue of Nepal 1255-2011 AD). Retrieved October 2, 2017, from

http://www.nset.org.np/nset2012/index.php/menus/subsubmenudetail/submenuid137/subsubmenuid-48/menuid-58

Parajuli, H. R. (2009). Dynamic Analyses of Low Strength Masonry Houses Based on Site Specific Earthquake Ground Motion. Kyoto University. Retrieved from https://doi.org/10.14989/doctor.k14556

Porto, F. da, Valluzzi, M. R., Munari, M., Modena, C., Arede, A., \& Costa, A. A. (2018). Strengthening of brick and stone masonry buildings. In A. Costa, A. Arêde, \& H. Varum (Eds.), Strengthening and Retrofitting of Existing Structures (Vol. 9). https://doi.org/10.1007/978-981-10-5858-5

The Kathmandu Post. (2017, March 15). NRA starts distribution of third installment of housing grant. Kantipur Publication. Kathmandu, Nepal. Retrieved from http://kathmandupost.ekantipur.com/news/2017-03-15/nra-starts-distribution-of-thirdinstallment-of-housing-grant.html

Thomos Bell. (2016). What's really holding back reconstruction in Nepal. Retrieved November 7, 2017, from http://www.aljazeera.com/indepth/opinion/2016/04/holding-reconstructionnepal-160424075649714.html

Triantafillou, T. C., \& Fardis, M. N. (1997). Strenthening of historic masonry structures with composite materials. Materials and Structures, 30, 486-496. 
UNDP. (2015). Earthquake in Nepal | UNDP. Retrieved October 7, 2017, from http://www.undp.org/content/undp/en/home/crisis-response/past-crises/nepal.html

Vieux-Champagne, F., Sieffert, Y., Grange, S., Polastri, A., Ceccotti, A., \& Daudeville, L. (2014). Experimental analysis of seismic resistance of timber-framed structures with stones and earth infill. Engineering Structures, 69, 102-115.

https://doi.org/10.1016/j.engstruct.2014.02.020

Vintzileou, E. (2008). Effect of Timber Ties on the Behavior of Historic Masonry. Journal of Structural Engineering, 134(June), 961-972. https://doi.org/10.1061/(ASCE)07339445(2008)134:6(961)

Yogeshwar K. Parajuli, Jitendra K. Bothara, Amod M. Dixit, Jyoti P. Pradhan, R. D. S. (2000). Nepal Building Code - Need, Development Philosophy and Means of Implementation. In 12Wce2000 (pp. 1-7). https://doi.org/10.13140/2.1.4100.7366 